\title{
Swallowing function and the incidence of fever in older residents with special care needs: a one-year longitudinal prospective study
}

Maya Izumi

Kyushu Dental University

Kazuo Sonoki

Kyushu Dental University

Yuko Ohta

Kyushu Dental University

Masayo Fukuhara

Kyushu Dental University

Masaharu Nagata

Shin-eikai Hospital

Sumio Akifusa ( $\nabla$ r11akifusa@fa.kyu-dent.ac.jp )

Kyushu Dental University https://orcid.org/0000-0001-7962-8762

Research article

Keywords: activities of daily living, fever, nursing home, swallowing

Posted Date: July 22nd, 2020

DOl: https://doi.org/10.21203/rs.3.rs-44731/v1

License: (1) This work is licensed under a Creative Commons Attribution 4.0 International License.

Read Full License 


\section{Abstract \\ Background}

Infectious diseases including aspiration pneumonia are the most frequent causes of fever, common in older residents of nursing homes. We investigated whether swallowing dysfunction was related to fever in such residents.

\section{Methods}

Older residents aged $\geq 65$ years from three nursing homes were included in this prospective study conducted from July 2017 to May 2019. The follow-up period was 13 months. The outcome was fever incidence in relation to swallowing function. Baseline data on the activities of daily living, cognitive function, swallowing function, respiratory function, tongue pressure, and comorbidity conditions were collected. Dates on which the body temperature of participants was more than $37.5^{\circ} \mathrm{C}$ during the followup period were also recorded. For statistical analysis, swallowing function assessed by the modified water swallow test (MWST) scores were used to divide the participants into three groups; scores $\leq 3,4$, and 5 .

\section{Results}

A total of 52 participants [median age, 89.5 (67-104)] were enrolled. Kaplan-Meier analysis showed that the average periods until onset of fever in participants with MWST scores of $\leq 3,4$, and 5 were 8.0 (6.011.0), 10.0 (7.0-12.0), and 12.0 (10.0-13.0) months, respectively. Cox's proportional hazards regression model revealed that participants with an MWST score $\leq 3$ were at a higher risk of fever compared to those with an MWST score of 5 (hazards ratio 13.0, 95\% confidence interval 1.9-87.6), adjusted with possible confounders.

\section{Conclusions}

Swallowing dysfunction correlated with the risk of fever in older residents of nursing homes.

\section{Background}

Fever is a cardinal clinical sign, especially in geriatric individuals. However, symptoms accompanying fever are frequently atypical, showing non-classical patterns[1, 2]. Since the immune function in geriatric individuals is compromised in comparison to younger individuals, an absent or blunted fever response in inflammatory diseases is often observed. In older individuals, bacteremia[3], endocarditis[4, 5], pneumonia[6, 7], and meningitis[8] often present with low-grade fever when compared to younger individuals. Infectious diseases are the most frequent nosogeny of fever; other causes being chronic 
inflammatory collagen diseases, tumors, and drug-related fevers $[9,10]$. A previous study reported that the proportion of severe infectious diseases is higher in older individuals than in younger individuals, and is associated with increased risk of morbidity and mortality [11]. In nursing homes, fever is more likely to occur in older residents with care needs, and pneumonia/bronchitis, urinary tract, skin, and soft tissue infections are the common causes $[12,13]$. The onset of fever, particularly at night, imposes a significant burden not only on the patients but also on medical professionals and the nursing home staff. Since most nursing homes lack the required human resources, the incidence and risk factors of fever should be thoroughly investigated. Thus, predictors of fever are the key to provide optimum health to geriatric individuals requiring care.

The swallowing function degrades with aging [14]. Although bolus transit time does not change with age, the swallow response time is often delayed in older individuals [15]. Swallowing dysfunction is a risk factor for malnutrition [16], aspiration [17], recurrent pneumonia [18, 19], and poor vital prognosis [20] in older individuals.

Hence, the aim of this study was to determine the factors associated with fever in older residents of nursing homes. Considering they show an increased risk of aspiration pneumonia, we further investigated whether swallowing function can predict the onset of fever in older individuals requiring special care.

\section{Methods}

\section{Study setting and study population}

This prospective cohort study was performed in three nursing-care insurance facilities in Kitakyushu City, Fukuoka Prefecture, Japan, from July 2017 to May 2019. The follow-up period was 13 months. Individuals who could not sit or communicate were excluded, as a spirometer was used for the accurate measurement of respiratory function. Fifty-seven geriatric residents aged $\geq 65$ years were enrolled, four refused to participate in the baseline survey, and one left the nursing home before onset of fever during the follow-up period. Finally, 52 residents were analyzed. A flow diagram showing the process of participant selection is shown in Fig. 1.

\section{Data collection}

Swallowing function, tongue pressure, activities of daily living (ADL), cognitive function, respiratory function, pneumococcus vaccination, and comorbidity conditions at baseline were assessed. During the follow-up period, dates, when the participant exhibited a body temperature of more than $37.5^{\circ} \mathrm{C}$, i.e., fever, were also recorded. Daily axillary temperature was measured at 7:00 am by the nursing home staff. Information on demographic characteristics, pneumococcal vaccination, and physical health status were obtained from a standard questionnaire and medical records of the nursing-care insurance facility. Data were collected from 3:00 pm to 5:00 pm at the participant's nursing home.

\section{Swallowing function}


Swallowing function was evaluated using the modified water swallow test (MWST), with sensitivity and specificity of $70 \%$ and $88 \%$, respectively, in predicting aspiration [21], one of the most significant consequences of dysphagia. A 10-mm syringe was used to pour $3 \mathrm{ml}$ cold water into the floor of the mouth of the participant, and he/she was instructed to swallow it. The swallowing was scored as follows: score 1, inability to swallow with choking and/or breathing changes; score 2 , swallowing complete, but with breathing changes; score 3 , swallowing complete with no breathing changes, but with choking and/or wet hoarseness; score 4, swallowed successfully with no choking and/or wet hoarseness; score 5, combined with meeting the requirements of score 4, additional deglutition (dry swallowing) was performed more than twice within $30 \mathrm{~s}$. If the score was equal to or above 4 (score 4 or score 5), the test was repeated twice, and the lowest score was considered. A score of $\leq 3$ indicated a risk of dysphagia. For statistical analysis, the participants were classified into three groups by MWST scores of $\leq 3,4$, and 5 .

\section{Maximum tongue pressure}

Tongue pressure was evaluated using a specific tongue pressure measurement device (JMS Co, TPM-01, Tokyo, Japan). TPM-01 is a handheld manometry device consisting of a small, balloon-type, disposable oral probe. At zero calibration, the probe is inflated with air at a pressure of $19.6 \mathrm{kPa}$. Tongue pressure was measured with the participants in a relaxed, seated position. They were instructed to compress the balloon-type probe between the tongue and palate with the maximum possible force. All measurements were performed by a single dental hygienist. The measurements were performed three times, and the maximum value was considered for the analysis.

\section{Peak expiratory flow rate}

A simple electronic spirometer (CHESTGRAPH HI-105; CHEST M. I., Tokyo, Japan) was used to measure the peak expiratory flow rate (PEFR). All measurements were performed by a single dental hygienist. Participants were asked to take a deep breath, and then exhale while sitting in an upright position to yield the highest PEFR. For each participant, the highest of three consecutive measurements was considered as the correct PEFR.

\section{ADL, cognitive activity, and comorbidity conditions}

Trained nursing home staff assessed the functional dependence in ADL using the Barthel index, which includes the domains of personal care and mobility. The scores ranged from 0 to 100, with higher scores representing greater independence. Cognitive function was assessed using the mini-mental state examination (MMSE), which includes the domains of registration, orientation, attention, concentration, memory, language, and ability to follow simple commands [22]. The total score ranged from 0 to 30 (higher scores represent better cognition). Comorbidity conditions were assessed with the Charlson comorbidity index $(\mathrm{CCl})[23,24]$ because older individuals were frequently affected by one or more diseases.

\section{Statistical analysis}


Descriptive statistics were used to characterize the participants. Each value was represented as median (minimum-maximum) and was evaluated using the Mann-Whitney $U$ test for continuous variables and the chi-square test for categorical variables. The incidence curves of initial onset of fever during the follow-up period were analyzed using the Kaplan-Meier method. The Cox proportional hazards model was used to estimate hazard ratios (HRs) for onset of fever among the three groups. The following variables were identified as possible confounders of the association between swallowing function and onset of fever: sex, age, ADL, body mass index, $C C l$, respiratory function, and tongue pressure. All analyses were performed using the SPSS statistical software version 22 (SPSS, Chicago, IL, USA), and the level of significance was set at $5 \%$ for all cases. We followed the STrengthening the Reporting of OBservational studies in Epidemiology (STROBE) guidelines for reporting the analysis of observational data.

\section{Results}

Data obtained from the 52 participants ( 11 male and 41 female) were analyzed. The median age of the participants was $89.5(67-104)$ years. The number of participants with MWST scores of $\leq 3,4$, and 5 were $13(25.0 \%), 17$ (32.7\%), and 22 (42.3\%), respectively. The baseline characteristics of participants according to the swallowing function are shown in Table. 1. Age, sex, Barthel index scores, MMSE scores, body mass index, tongue pressure, $\mathrm{CCl}$ scores, and comorbidities except cancer showed no statistical differences across the three groups. The group with an MWST score $\leq 3$ included three participants with cancer $(p=0.008)$. Respiratory function, assessed by PEFR, showed significant statistical difference among the three groups; PEFR in the group with an MWST score of 5 was significantly higher than those in other groups. MWST scores and PEFR were significantly correlated $(r=0.463, p=0.001$, analyzed by the Spearman's rank correlation coefficient).

The empirical incidence curves of initial fever during the follow-up period for the three groups are shown in Fig. 2. The incidence of initial fever in the group with an MWST score $\leq 3$ markedly increased at 6 and 8 months. During the follow-up period, 29 initial fevers in 1251.5 person-years were observed. The group with an MWST score $\leq 3$ showed significantly higher initial fevers per person-years than the group with an MWST score of 5 (Table 2). The average periods until fever in groups with MWST scores of $\leq 3,4$, and 5 were 12.0 (95\% confidence interval (Cl) 10.0-13.0) months, 10.0 (95\% Cl 7.0-12.0) months, and 8.0 (95\% Cl 6.0-11.0) months, respectively (Table 2). The median number of days of initial fever in the participants was $1.0(1-5)$. In $51.7 \%$ participants, the initial fever period was of 1 day. No participant was hospitalized due to pneumonia during the follow-up period. In the three participants with cancer, two participants exhibited fever, while one did not. 
Table 1

Characteristics of participants divided by swallowing function

\begin{tabular}{|c|c|c|c|c|}
\hline \multirow[t]{2}{*}{ Independent variable } & \multicolumn{3}{|l|}{ MWST } & \multirow[t]{2}{*}{$\mathrm{p}$ value } \\
\hline & $<3(n=13)$ & $4(n=17)$ & $5(n=22)$ & \\
\hline Age, $m$ (min-max) & $90.5(79-96)$ & $89.5(67-104)$ & $89(67-97)$ & $0.855^{\dagger}$ \\
\hline $\begin{array}{l}\text { Barthel index, } \\
m \text { (min-max) }\end{array}$ & $42.5(10-75)$ & $37.5(10-75)$ & $32.5(5-70)$ & $0.278^{\dagger}$ \\
\hline MMSE, $m$ (min-max) & $14.5(5-28)$ & $13(0-29)$ & $17(3-28)$ & $0.618^{\dagger}$ \\
\hline BMI, $m$ (min-max) & $20.4(14.2-31.6)$ & $19.2(13.4-31.6)$ & $20.0(12.8-28.2)$ & $0.858^{\dagger}$ \\
\hline $\mathrm{CCl}, m$ (min-max) & $2(0-4)$ & $1.5(0-3)$ & $1(0-3)$ & $0.229^{\dagger}$ \\
\hline PEFR, $m$ (min-max) & $1.16(0.49-1.81)^{\star *}$ & $1.38(0.14-4.58)^{*}$ & $1.87(0.72-4.68)$ & $0.004^{\dagger}$ \\
\hline $\begin{array}{l}\text { Tongue pressure, } \\
m \text { (min-max) }\end{array}$ & $12.8(2.8-25.7)$ & $15.1(4.2-35.2)$ & $17.9(1.7-44.4)$ & $0.482^{+}$ \\
\hline \multicolumn{5}{|l|}{ Sex, $n(\%)$} \\
\hline Man & $3(23.1)$ & $1(5.9)$ & $7(31.8)$ & \multirow[t]{2}{*}{$0.142^{\ddagger}$} \\
\hline Woman & $10(76.9)$ & $16(94.1)$ & $15(68.2)$ & \\
\hline \multicolumn{5}{|l|}{ Comorbidity, $n$ (\%) } \\
\hline Myocardial infarction & $4(30.8)$ & $3(17.6)$ & 4 (18.2) & $0.618^{\ddagger}$ \\
\hline Cardiac insufficiency & $4(30.8)$ & $7(41.2)$ & $2(9.1)$ & $0.062^{\ddagger}$ \\
\hline Cerebrovascular disease & $2(15.4)$ & $8(47.1)$ & $4(18.2)$ & $0.073^{\ddagger}$ \\
\hline Dementia & $2(15.4)$ & $4(23.5)$ & $8(36.4)$ & $0.372^{\ddagger}$ \\
\hline Chronic hepatitis & $0(0)$ & $0(0)$ & $1(4.5)$ & $0.499^{\ddagger}$ \\
\hline Diabetes mellitus & $3(23.1)$ & $4(23.5)$ & $6(27.3)$ & $0.948^{\ddagger}$ \\
\hline Cancer & $3(23.1)$ & $0(0)$ & $0(0)$ & $0.008^{\ddagger}$ \\
\hline Pneumococcal vaccination & $4(30.8)$ & $3(17.6)$ & $3(13.6)$ & 0.453 \\
\hline \multicolumn{5}{|c|}{$\begin{array}{l}{ }^{\dagger} \text { Kruskal Wallis test, }{ }^{\ddagger}: \text { chi square test, }{ }^{*} p<0.05 \text { compared to MWST } 5,{ }^{* \star} \mathrm{p}<0.01 \text { compared to MWST } \\
\end{array}$} \\
\hline
\end{tabular}


Table 2

Incidence of fever per person-years, period until fever, and hazard ratio for fever by MWST

\begin{tabular}{|c|c|c|c|c|c|}
\hline \multirow[t]{2}{*}{ MWST } & \multirow[t]{2}{*}{$\begin{array}{l}\text { Incidence of fever per person- } \\
\text { years }\end{array}$} & \multirow[t]{2}{*}{$\begin{array}{l}\mathrm{p}- \\
\text { value }^{\dagger}\end{array}$} & \multirow{2}{*}{$\begin{array}{l}\begin{array}{l}\text { Average of } \\
\text { period }\end{array} \\
\text { until fever } \\
(95 \% \mathrm{Cl})^{\ddagger}\end{array}$} & \multicolumn{2}{|c|}{$\begin{array}{l}\text { Cox proportional hazard } \\
\text { model }\end{array}$} \\
\hline & & & & $\mathrm{HR}(95 \% \mathrm{Cl})^{\S}$ & p-value \\
\hline 5 & $0(0-0.50)$ & 0.022 & $\begin{array}{l}12.0(10.0- \\
13.0)\end{array}$ & 1 & 0.009 \\
\hline 4 & $0.77(0-0.17)$ & & $\begin{array}{l}10.0(7.0- \\
12.0)\end{array}$ & $1.6(0.5-5.4)$ & 0.427 \\
\hline$\leq 3$ & $0.77(0-0.33)^{*}$ & & $8.0(6.0-11.0)$ & $12.9(2.0-82.6)$ & 0.007 \\
\hline \multicolumn{6}{|c|}{ HR: hazard ratio, Cl: confidence interval, MWST: modified water swallowing test. } \\
\hline \multicolumn{6}{|c|}{$\begin{array}{l}{ }^{\dagger}{ } \text { Kruskal Wallis test, }{ }^{*} p<0.05 \text { compared to MWST } 5 \text { assessed by post-hoc analysis of Kruskal Wallis } \\
\text { test, }{ }^{\ddagger} \text { Obtained from Kaplan-Meier model. } § \text { Adjusted by sex, age, activity of daily living, cognitive } \\
\text { function, body mass index, Charlson comorbidity index, tongue pressure, respiratory function, and } \\
\text { pneumococcus vaccination. }\end{array}$} \\
\hline
\end{tabular}

In the Cox regression models, the HR for initial fever in the group with an MWST score $\leq 3$ was 13.0 (95\% $\mathrm{Cl} 1.9-87.6, p=0.009)$ compared to the group with an MWST score of 5 , adjusted by possible confounders (Table 2).

\section{Discussion}

The findings of this study were analyzed by the Cox proportional hazard model adjusted with possible confounders. The model demonstrated that swallowing dysfunction, assessed by MWST, increased the risk of fever, which was designated as a body temperature of $37.5^{\circ} \mathrm{C}$ and above, in older Japanese residents of nursing homes.

In this study, $51.7 \%$ of participants had a fever period of one day, which is consistent with previous reports demonstrating that the proportion of one-day fever was $47.5 \%$ in all fever episodes in elderly inpatients [25]. A study previously reported that the most common nosogeny of fever in older inpatients was infectious diseases: respiratory tract infection (34.5\%), urinary tract infections, $(23.8 \%)$, other infectious diseases (12.2\%), and infections of unknown origin (26.9\%) [26]. Similarly, another study reported that the most common nosogenies of fever in patients of the recovery phase rehabilitation ward were respiratory tract (60.2\%) and urinary tract infections (27.8\%) [27]. As quoted by Sir William Osler, "pneumonia is the friend of the aged," a frequent, painless, and lethal event occurring in elderly patients [28]. Although the nosogeny of fever was not determined in the nursing home residents of this study, as shown by these multiple lines of evidence, the predominant cause of fever is expected to be respiratory tract infection. The risk factors of pneumonia in older residents of long-term care facilities were identified 
as individual (malnutrition, long-term disease, functional impairment, medications, and prolonged antimicrobial exposure) and institutional (larger facilities with shared nursing staff, group activities, low immunization rates, and excessive anti-microbial use) factors [29]. Swallowing dysfunction is also closely related to aspiration pneumonia in older adults $[19,30]$. Most older individuals tend to dismiss dysphagia as a symptom of normal aging [31]. However, though swallowing function declines with age $[32,33]$, regular examinations are critical to maintain the swallowing function and to prevent onset of fever in older individuals with the need for care. Our findings suggest that older individuals with swallowing dysfunction should be taken in account for onset of fever caused by pneumonia in the nursing home.

According to the clinical practice guideline for evaluation of fever and infection in older adult residents of long-term care facilities established by the infectious diseases society of America, the following types of fever are signs of suspected infection: (1) A single oral temperature $>37.8^{\circ} \mathrm{C}$; or (2) repeated oral temperatures $>37.2^{\circ} \mathrm{C}$ or rectal temperatures $>37.5^{\circ} \mathrm{C}$; or (3) an increase in temperature of $>1.1{ }^{\circ} \mathrm{C}$ above the baseline temperature[34]. The response to infectious assault in older individuals tends to be atypical with no fever episodes. A decrease in immune cells, followed by a reduction in innate pyrogen and inactivation of arachidonic acid metabolism $[35,36]$ is frequently observed with aging. Since the normal body temperature in older individuals is generally lower than that of younger individuals, the fever threshold should be estimated at a lower value. The mortality rate in older individuals with body temperature $\geq 37.5^{\circ} \mathrm{C}$ or $\geq 1.5^{\circ} \mathrm{C}$ above the usual body temperature has been reported to be $5 \%$ [37]. In older individuals, if fever is defined as a body temperature of $\geq 37.2^{\circ} \mathrm{C}$, the sensitivity and specificity of detecting infections become $83 \%$ and $89 \%$, respectively[38]. This evidence suggests that even a slight pyrexic event can lead to poor vital prognosis in older individuals. Considering that pyrexia in older individuals can be easily missed, individuals with swallowing dysfunction should be monitored more attentively. In our study, the proportion of participants with $\leq 3$ was $25.0 \%$. In a previous study, the proportion was $18.5 \%$ in older residents of nursing homes[39]. The evidences strongly suggest there are many older individuals with a high risk of pneumonia in nursing homes.

This study has some limitations. First, we did not evaluate the causes of fever. Since most fever episodes are short-term, the nosogeny of fever is not determined in nursing homes. Second, we recruited participants from three nursing homes of two mid-sized cities in Japan. Therefore, caution is warranted in generalizing our findings to the wider older Japanese population. Third, fever was defined as a body temperature of $\geq 37.5^{\circ} \mathrm{C}$ in this study. Hence, fever episodes in participants with lower normal body temperatures might have been overlooked. For the precise evaluation of such patients, it is necessary to collect data on pyrexia with body temperature of $>1.5^{\circ} \mathrm{C}$ from the normal. A strength of this study is that variables used for analyses employed biological data such as tongue pressure, PEFR, and MWST for analyzing oral functions. Another study had employed a questionnaire, the EAT-10 [40, 41], for analyzing the swallowing function. To the best of our knowledge, this is the first study that attempts to determine the relationship between swallowing function and fever incidence in older residents of nursing homes. Our findings will help in the implementation of adequate precautionary measures such as swallowing training for older individuals with high incidences of fever. Hence, further research should be 
interventional trials to investigate the effect of training and/or rehabilitation of swallowing function on fever incidence.

\section{Conclusions}

Swallowing dysfunction increased the risk of fever, defined as a body temperature of $\geq 37.5^{\circ} \mathrm{C}$, during a 13-month follow-up period in older Japanese residents of nursing homes. The findings of the study suggest that many older nursing home residents with the need for care have the risk of pneumonia.

\section{Abbreviations}

CCI: Charlson comorbidity index; MMSE:mini-mental state examination; MWST:modified water swallowing test; PEFR:peak expiratory flow rate

\section{Declarations}

\section{Ethics approval and consent to participate}

The study was approved by the Kyushu Dental University Institutional Review Board for Clinical Research (No. 17 - 1). Informed consent was obtained from all respondents, their surrogates, or legal representatives before data collection.

\section{Consent for publication}

Not applicable.

\section{Availability of data and materials}

Data and material are available by the corresponding author on reasonable request.

\section{Competing interests}

The authors declare that they have no competing interests.

\section{Funding}

This study was partially supported by the Ministry of Education, Science, Sports and Culture, Grant-in-Aid for Scientific Research(C), 2018-2020 (18K17292, Maya Izumi).

\section{Authors' contributions}


All authors had significant roles in designing, conceiving, and conducting the study and drafting the manuscript. MI and SA contributed to designing the study. MI, KS, YO and MN collected the data, and SA analyzed it. MF and SA were the supervisor of the whole research and checked the data. The final report and article were written by IM and SA. All authors read and approved the final manuscript.

\section{Acknowledgments}

We wish to thank the participants of this study and support staff who made the study possible

\section{References}

1. Norman DC. Fever in the elderly. Clinical infectious diseases: an official publication of the Infectious Diseases Society of America. 2000;31(1):148-51.

2. Norman DC, Yoshikawa TT. Fever in the elderly. Infect Dis Clin North Am. 1996;10(1):93-9.

3. Gleckman R, Hibert D. Afebrile bacteremia: a phenomenon in geriatric patients. JAMA. 1981;14:7881.

4. Terpenning MS, Buggy BP, Kauffman CA. Infective endocarditis: clinical features in young and elderly patients. Am J Med. 1987;83(4):626-34.

5. Werner GS, Schulz R, Fuchs JB, Andreas S, Prange H, Ruschewski W, Kreuzer H. Infective endocarditis in the elderly in the era of transesophageal echocardiography: clinical features and prognosis compared with younger patients. Am J Med. 1996;100(1):90-7.

6. Finkelstein MS, Petkun WM, Freedman ML, Antopol SC. Pneumococcal bacteremia in adults: agedependent differences in presentation and in outcome. J Am Geriatr Soc. 1983;31(1):19-27.

7. Marrie TJ, Haldane EV, Faulkner RS, Durant $H$, Kwan C. Community-acquired pneumonia requiring hospitalization. Is it different in the elderly? J Am Geriatr Soc. 1985;33(10):671-80.

8. Gorse GJ, Thrupp LD, Nudleman KL, Wyle FA, Hawkins B, Cesario TC. Bacterial meningitis in the elderly. Arch Intern Med. 1984;144(8):1603-7.

9. Mulders-Manders CM, Simon A, Bleeker-Rovers CP. Rheumatologic diseases as the cause of fever of unknown origin. Best Pract Res Clin Rheumatol. 2016;30(5):789-801.

10. Tal S, Guller V, Gurevich A, Levi S. Fever of unknown origin in the elderly. J Intern Med. 2002;252(4):295-304.

11. Keating HJ 3rd, Klimek JJ, Levine DS, Kiernan FJ. Effect of aging on the clinical significance of fever in ambulatory adult patients. J Am Geriatr Soc. 1984;32(4):282-7.

12. Yokobayashi K, Matsushima M, Fujinuma Y, Tazuma S. Retrospective cohort study of the incidence and risk of fever in elderly people living at home: A pragmatic aspect of home medical management in Japan. Geriatrics Gerontology International. 2013;13(4):887-93.

13. Garibaldi RA. Residential care and the elderly: the burden of infection. J Hosp Infect. 1999;43 Suppl:9-18. 
14. Mulheren RW, Azola AM, Kwiatkowski S, Karagiorgos E, Humbert I, Palmer JB, Gonzalez-Fernandez M. Swallowing Changes in Community-Dwelling Older Adults. Dysphagia. 2018;33(6):848-56.

15. Namasivayam-MacDonald AM, Barbon CEA, Steele CM. A review of swallow timing in the elderly. Physiol Behav. 2018;184:12-26.

16. Jardine M, Miles A, Allen JE. Swallowing function in advanced age. Curr Opin Otolaryngol Head Neck Surg. 2018;26(6):367-74.

17. Marik PE, Kaplan D. Aspiration pneumonia and dysphagia in the elderly. Chest. 2003;124(1):328-36.

18. Mitani Y, Oki Y, Fujimoto Y, Yamaguchi T, Yamada Y, Yamada K, Ito T, Shiotani H, Ishikawa A. Relationship between the Functional Independence Measure and Mann Assessment of Swallowing Ability in hospitalized patients with pneumonia. Geriatr Gerontol Int. 2018;18(12):1620-4.

19. Marik PE, Kaplan D. Aspiration pneumonia and dysphagia in the elderly. Chest. 2003;124(1):328-36.

20. Naruishi K, Nishikawa Y. Swallowing impairment is a significant factor for predicting life prognosis of elderly at the end of life. Aging Clin Exp Res. 2018;30(1):77-80.

21. Tohara H, Saitoh E, Mays KA, Kuhlemeier K, Palmer JB. Three tests for predicting aspiration without videofluorography. Dysphagia. 2003;18(2):126-34.

22. Folstein MF, Folstein SE, McHugh PR. "Mini-mental state". A practical method for grading the cognitive state of patients for the clinician. J Psychiatr Res. 1975;12(3):189-98.

23. Christensen $S$, Johansen MB, Christiansen CF, Jensen R, Lemeshow S. Comparison of Charlson comorbidity index with SAPS and APACHE scores for prediction of mortality following intensive care. Clin Epidemiol. 2011;3:203-11.

24. Charlson ME, Pompei P, Ales KL, MacKenzie CR. A new method of classifying prognostic comorbidity in longitudinal studies: development and validation. J Chronic Dis. 1987;40(5):373-83.

25. Ikematsu H, Yamaga S, Nabeshima A, Yamaji K, Kakuda K, Ueno K, Hayashi J, Hara H, Shirai T, Kashiwagi S. [Incidence and duration of febrile episodes in a hospitalized geriatric cohort]. Kansenshogaku Zasshi. 1996;70(10):1079-85.

26. Ueno K, Hayashi J, Yamaga S, Ikematsu H, Nabeshima A, Hara H, Kashiwagi S. [Febrile episodes in elderly inpatients-a one year survey to determine the causes of fever in hospital]. Kansenshogaku Zasshi. 1998;72(5):493-8.

27. Ohse H, Ito T, Saito K, Kohno Y, Kobayashi M, Takeuchi R, Shimizu Y, Matsuzaki H, Wadano Y: Examination of the exothermic cases in the recovery rehabilitation unit of our hospita1. The medical journal of Ibaraki Prefectural Hospitals 2014, 31(1):23-27.

28. Osler W. The Principles and Practice of Medicine. New York: D. Appleton \& Company; 1898.

29. Richards C. Infections in residents of long-term care facilities: an agenda for research. Report of an expert panel. J Am Geriatr Soc. 2002;50(3):570-6.

30. Kikawada M, Iwamoto T, Takasaki M. Aspiration and infection in the elderly: epidemiology, diagnosis and management. Drugs Aging. 2005;22(2):115-30. 
31. Nawaz S, Tulunay-Ugur OE. Dysphagia in the Older Patient. Otolaryngol Clin North Am. 2018;51(4):769-77.

32. Azzolino D, Damanti S, Bertagnoli L, Lucchi T, Cesari M. Sarcopenia and swallowing disorders in older people. Aging Clin Exp Res. 2019;31(6):799-805.

33. Jardine M, Miles A, Allen JE. Swallowing function in advanced age. Curr Opin Otolaryngol Head Neck Surg. 2018;26(6):367-74.

34. High KP, Bradley SF, Gravenstein S, Mehr DR, Quagliarello VJ, Richards C, Yoshikawa TT. Clinical practice guideline for the evaluation of fever and infection in older adult residents of long-term care facilities: 2008 update by the Infectious Diseases Society of America. Clin Infect Dis. 2009;48(2):149-71.

35. Jones PG, Kauffman CA, Bergman AG, Hayes CM, Kluger MJ, Cannon JG. Fever in the elderly. Production of leukocytic pyrogen by monocytes from elderly persons. Gerontology. 1984;30(3):1827.

36. Norman DC, Grahn D, Yoshikawa TT. Fever and aging. J Am Geriatr Soc. 1985;33(12):859-63.

37. Yokobayashi K, Matsushima M, Watanabe T, Fujinuma Y, Tazuma S. Prospective cohort study of fever incidence and risk in elderly persons living at home. BMJ Open. 2014;4(7):e004998.

38. Castle SC, Yeh M, Toledo S, Yoshikawa TT, Norman DC. Lowering the temperature criterion improves detection of infections in nursing home residents. Aging: Immunology Infectious Disease. 1993;4(2):67-76.

39. Okabe Y, Takeuchi K, Izumi M, Furuta M, Takeshita T, Shibata Y, Kageyama S, Ganaha S, Yamashita Y. Posterior teeth occlusion and dysphagia risk in older nursing home residents: a cross-sectional observational study. J Oral Rehabil. 2017;44(2):89-95.

40. Igarashi K, Kikutani T, Tamura F: Survey of suspected dysphagia prevalence in home-dwelling older people using the 10-Item Eating Assessment Tool (EAT-10). PLoS One 2019, 14(1):e0211040.

41. Wakabayashi H, Matsushima M. Dysphagia Assessed by the 10-Item Eating Assessment Tool Is Associated with Nutritional Status and Activities of Daily Living in Elderly Individuals Requiring LongTerm Care. J Nutr Health Aging. 2016;20(1):22-7.

\section{Figures}




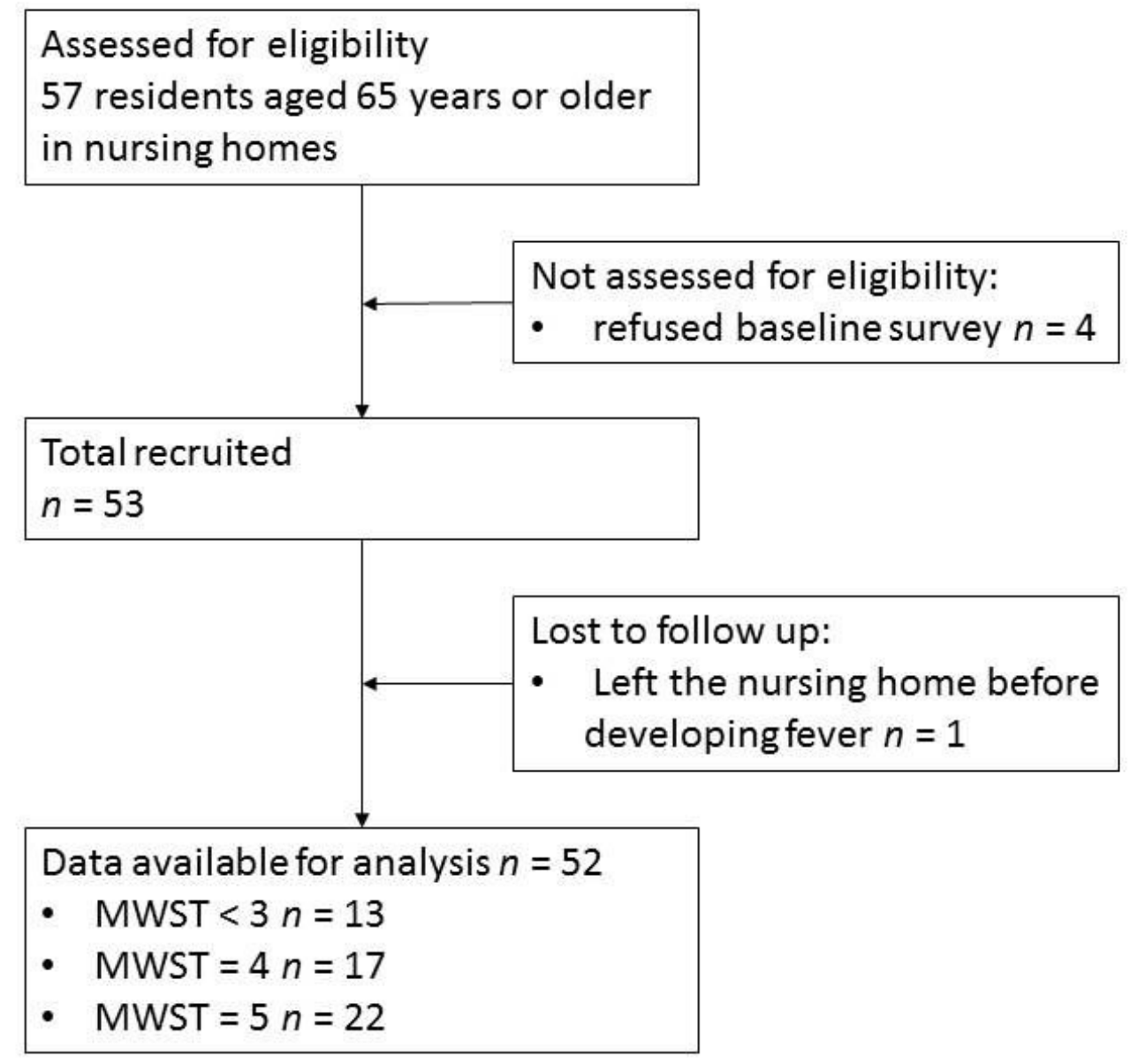

Fig. 1

Figure 1

Flow diagram of the study participants. 


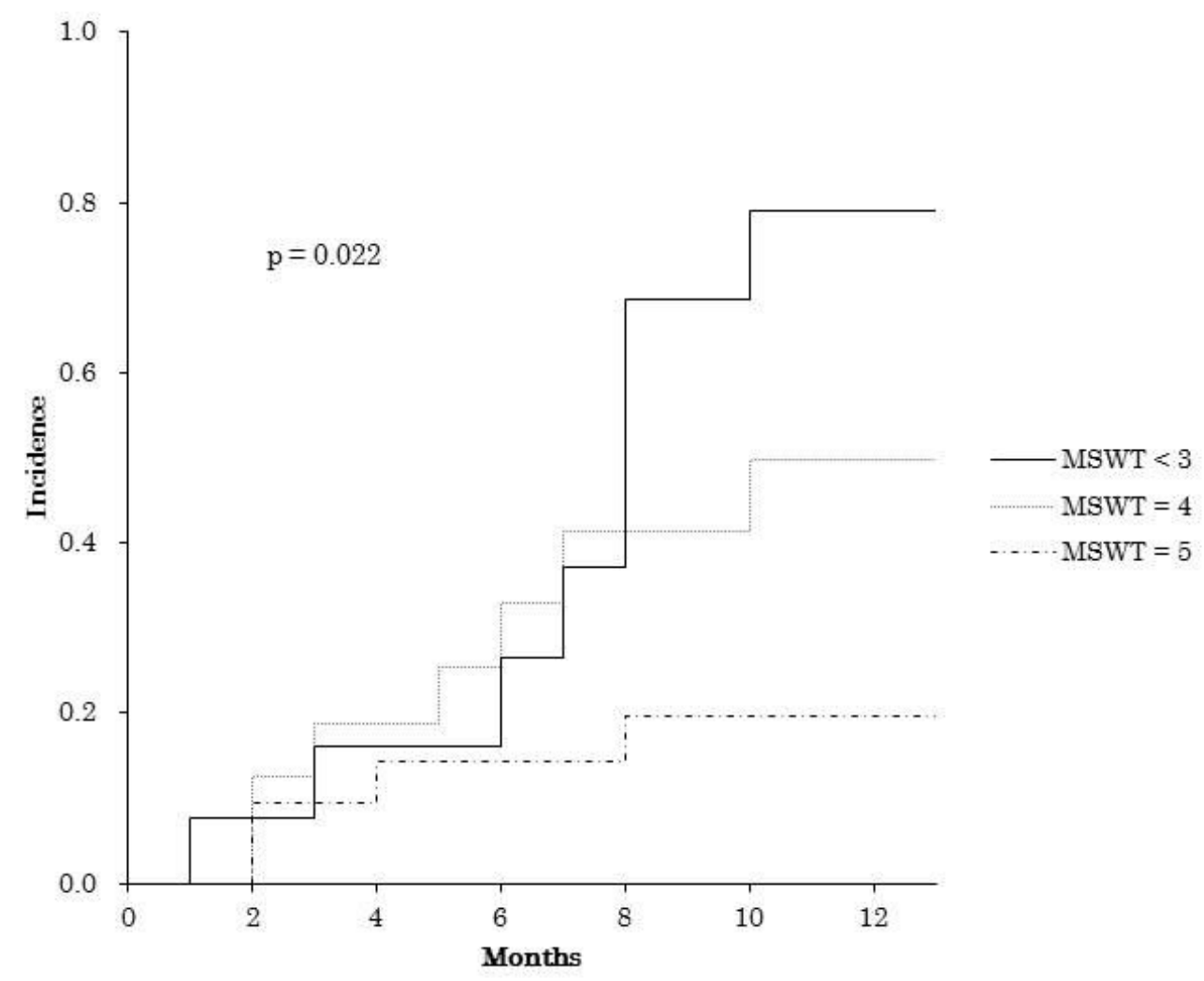

Fig. 2

Figure 2

Incidence curves according to the swallowing function. The x-axis shows the follow-up duration (months). (-) MWST <3, (-) MSWT = 4, (-) MSWT = 5 